\title{
HUBUNGAN PENERAPAN ASUHAN SAYANG IBU PADA PERSALINAN KALA II DENGAN KEJADIAN ROBEKAN JALAN LAHIR
}

\author{
Beatric Maria Dwi Jayanti Baga* \\ STIKes William Booth Surabaya, Jln. Cimanuk No.20, Telp.(031) 5633365 \\ e-mail: stikes_williambooth@ymail.com
}

\begin{abstract}
ABSTRAK
Pendahuluan: Rupture perineum (robekan jalan lahir) biasa dapat berubah menjadi kasus rupture perineum dengan tingkat lebih berat dan penyebab terjadinya kejadian kematian pada ibu bersalin apabila penatalaksanaan tidak dilakukan dengan baik dan tanggap. Rupture perineum dapat terjadi secara spontan maupun buatan pada persalinan normal (pervaginam) pada ibu bersalin primigravida saat pengeluaran kepala bayi. Tujuan penelitian ini adalah menganalisis hubungan penerapan asuhan sayang ibu pada persalinan kala II dengan kejadian robekan jalan lahir di RSIA Kirana Sepanjang Sidoarjo. Metode: Penelitian ini merupakan penelitian jenis observasional analitik dengan menggunakan pendekatan cross sectional. Variabel independen asuhan sayang ibu, variabel dependen kejadian robekan jalan lahir, populasi sebanyak 35 ibu bersalin, sampel 31 ibu bersalin, instrument penelitian lembar observasi, analisis data exact fisher's, $\alpha=0,05$. Hasil: 28 (32.3\%) ibu bersalin yang mendapatkan asuhan sayang ibu yang terdiri dari 7 (22.6\%) ibu bersalin mengalami robekan jalan lahir dan $21(9.7 \%)$ ibu bersalin tidak mengalami robekan jalan lahir, sedangkan $3(67,7 \%)$ ibu bersalin yang tidak mendapatkan asuhan sayang ibu semua mengalami robekan jalan lahir. Dengan nilai probabilitas $(p)=0.027$ dan $\leq \alpha$ maka $\mathrm{H}_{0}$ ditolak, $\mathrm{H}_{\mathrm{i}}$ diterima. Diskusi: Dari hasil penelitian dapat disimpulkan bahwa terdapat hubungan penerapan asuhan sayang ibu pada persalinan kala II dengan kejadian robekan jalan lahir, untuk itu perlu adanya komunikasi yang baik dan ramah bagi bidan dan pasien.
\end{abstract}

Kata kunci: Asuhan Sayang Ibu, Robekan Perineum

\begin{abstract}
Introduction: Ordinary perineal rupture (tear of the birth canal) can turn into a more severe case of perineal rupture and the cause of death in the mother if the management is not well done and responsive. Perineal rupture can occur spontaneously or artificially in normal (vaginal) labor in primigravida maternity at the time of excretion of the baby's head. The purpose of this study was to analyze the relationship between the application of care to the mother of second childbirth with the incidence of road tears born at RSIA Kirana Sepanjang Sidoarjo. Method: This study was an observational analytic study using a cross sectional approach. The independent variable of care for mother's love, the dependent variable of the incidence of birth canal tears, a population of 35 mothers of birth, a sample of 31 mothers giving birth, research instruments observation sheet, exact fisher's data analysis, $\alpha=0.05$. Results: 28 (32.3\%) mothers who received maternal care consisting of $7(22.6 \%)$ maternal births had a birth canal tear and 21 (9.7\%) women had no birth canal tears, while $3(67.7 \%)$ mothers who do not get care unfortunately mothers all experience a tear in the birth canal. With probability values $(\mathrm{p})=0.027$ and $\leq \alpha$ then $\mathrm{HO}$ is rejected, $\mathrm{Hi}$ is accepted. Discussion: From the results of the study, it can be concluded that there is a relationship between the application of care for the mother of the second childbirth and the occurrence of the tear of the birth canal, for that there is a need for good and friendly communication for midwives and patients.
\end{abstract}

Keywords: Dear Mother's care, Rips Perineum 


\section{PENDAHULUAN}

Masalah yang sedang dihadapi oleh Negara Indonesia pada sistem kesehatan saat ini adalah adanya peningkatan jumlah mortalitas dan morbiditas yang masih sulit untuk dicapai penurunannya. Pada umumnya peningkatan jumlah komplikasi serta penyulit pada ibu dan bayi menjadi penyebab tidak dapat terhindarnya kematian ibu dan bayi, padahal kematian ibu dan bayi dapat dihindari apabila prosedur yang dilakukan dikelola dengan tepat dan cepat. Dalam memberikan asuhan pada ibu bersalin, peran bidan dituntut untuk dapat melakukan dan menerapkan pedoman Asuhan Sayang Ibu selama berlangsungnya proses persalinan guna meningkatkan serta mengembangkan mutu asuhan.

Tahun 2015 SDKI mencatat bahwa AKI di Indonesia masih berkutat di angka 305/100.000 kelahiran hidup dan jumlah ini masih jauh dari target yang ditetapkan oleh MDGs' yakni 102/100.000 kelahiran hidup. Jawa Timur pada tahun 2015 mempunyai nilai AKI 89,6/100.000 kelahiran hidup, dan di Kabupaten Sidoarjo mempunyia nilai AKI 76/100.00 kelahiran hidup (Profil Dinkes Jatim, 2016). Secara langsung, penyebab kematian maternal di Indonesia yang terjadi pada ibu dalam masa hamil dan bersalin adalah eklampsia yang menduduki tingkat pertama penyebab kematian maternal dengan nilai $30 \%$, diikuti dengan perdarahan sejumlah $25 \%$, penyakit jantung sebanyak $12 \%$, infeksi $6 \%$, dan penyebab lain-lain sebanyak 26\% (Depkes, 2015).

Asuhan yang sangat berpengaruh dalam proses persalinan Asuhan Sayang Ibu. Asuhan ini merupakan asuhan yang menerapkan rasa simpati dan empati kepada pasien yang meliputi rasa menghargai kepercayaan, kebudayaan, serta keinginan dari ibu bersalin. Dalam memberikan asuhan kepada ibu bersalin hendaknya kita menanyakan kepada diri kita pribadi mengenai jenis dan macam asuhan yang kita inginkan untuk diri kita sendiri disaat jika diri kita nanti yang berada dan mendapatkan asuhan tersebut dengan menanyakan kepada diri kita sendiri. Asuhan saya ibu ini lebih ditekankan kepada ibu sebagai objek, bukan bidan, serta selalu melihat terlebih dahulu bagaimana cara pengobatan yang dilakukan secara sederhana sebelum dilakukan secara modern menggunakan tekhnologi.
Rupture perineum (robekan jalan lahir) biasa dapat berubah menjadi kasus rupture perineum dengan tingkat lebih berat dan penyebab terjadinya kejadian kematian pada ibu bersalin apabila penatalaksanaan tidak dilakukan dengan baik dan tanggap. Rupture perineum dapat terjadi secara spontan maupun buatan pada persalinan normal (pervaginam) pada ibu bersalin primigravida saat pengeluaran kepala bayi. Selain itu, berapapun tingkat terjadinya rupture juga menyebabkan terjadinya kehilangan banyak darah pada ibu nifas apabila robekan yang didapat saat proses persalinan tidak dijahit (diabaikan), hal ini dikarenakan darah yang keluar tidak secara langsung melainkan perlahan-lahan dan berlangsung selama berjam-jam tanpa diketahui dan dirasakan karena keluar bersamaan dengan lokhea (Carey, 2005).

Kejadian rupture perineum pada ibu bersalin perlu mendapatkan perhatian dari petugas kesehatan, terutama bidan, dikarenakan hal tersebut dapat mengakibatkan terjadinya beberapa hal diantaranya sebagai jalan masuk keluarnya infeksi, terjadinya disfungsi pada organ reproduksi wanita, penyebab perdarahan yang dimana dapat berlanjut pada kejadian sepsis bahka kematian (Manuaba, 2008).

Definisi perineum yang dikemukakan Herdiana, 2007, didalam bukunya menjelaskan bahwa perineum merupakan bagian kulit yang terdapat diantara area vagina dengan anus yang dapat terobek secara spontan maupun buatan (episiotomi) saat proses persalinan agar bayi dapat keluar. Rupture perineum yang terjadi akibat robekan buatan (episiotomi) dilakukan berdasarkan atas indikasi yang didapatkan pada saat persalinan, antara lain: persalinan dengan alat, ditemukannya kekakuan pada perineum, persalinan dengan letak lintang atau sungsang, bayi besar. Jika terdapat salah satu indikasi diatas maka harus dilakukan robekan perineum buatan (episiotomi) agar peningkatan terjadinya kerusakan pada daerah perineum dapat diminimalisir dengan cepat, karena apabila tidak segera dilaksanakan maka kerusakan yang terjadi akan mengarah pada kerusakan perineum berat pada ibu bersalin dan hasil akhir dari kejadian tersebut adalah adanya gangguan rasa nyaman pada ibu nifas akibat nyeri robekan pada perineum. 
Berdasarkan dari data yang diperoleh dari catatan medis di RSIA Kirana Sepanjang Sidoarjo pada bulan Januari-Desember 2016 di RSIA Kirana Sepanjang Sidoarjo ditemukan dari 289 ibu bersalin, 34 ibu bersalin mengalami robekan jalan lahir. 15 ibu mengalami robekan jalan lahir tingkat 1 , 19 ibu mengalami robekan jalan lahir tingkat 2 termasuk episiotomi. Asumsi peneliti ada beberapa hal yang berhubungan dengan terjadinya robekan jalan lahir. Dari uraian diatas maka penulis bermaksud untuk melakukan penelitian tentang hubungan penerapan asuhan sayang ibu pada persalinan kala II dengan kejadian robekan jalan lahir di RSIA Kirana Sepanjang Sidoarjo.

\section{BAHAN DAN METODE}

Jenis penelitian observasional analitik yang menggunakan pendekatan cross sectional untuk pengambilan sampling penelitian ini dilaksanakan pada bulan November 2017 - Januari 2018, dengan populasi sejumlah 34 ibu bersalin dan sampel 31 ibu bersalin di RSIA Kirana, Sidoarjo. Teknik sampling menggunakan simple random sampling.

Variabel penelitian adalah asuhan sayang ibu dan kejadian robekan jalan lahir. Data dikumpulkan dari observasi pada saat dilakukan penelitian dan rekam medik RSIA Kirana, Sidoarjo. Selanjutnya data dianalisis dengan uji Exact Fisher's $(\alpha=0,05)$.

\section{HASIL}

\section{Usia Ibu Bersalin}

Tabel 1 Frekuensi Usia Ibu Bersalin di RSIA Kirana, Sidoarjo

\begin{tabular}{lcc}
\hline \multicolumn{1}{c}{ Usia } & $\mathrm{f}$ & $\%$ \\
\hline$<20$ tahun & 2 & 6,4 \\
$20-35$ tahun & 25 & 80,6 \\
$>35$ tahun & 4 & 13 \\
Jumlah & 31 & 100 \\
\hline
\end{tabular}

Tabel 1 dapat dilihat bahwa mayoritas usia ibu bersalin adalah 20-35 tahun sebanyak 25 orang $(80,6 \%)$.

\section{Pendidikan Ibu Bersalin}

Tabel 2 Frekuensi Pendidikan Ibu Bersalin di RSIA Kirana, Sidoarjo

\begin{tabular}{lcc}
\hline \multicolumn{1}{c}{ Pendidikan } & $\mathrm{f}$ & $\%$ \\
\hline Dasar & 5 & 16 \\
Menengah & 23 & 74 \\
Tinggi & 3 & 10 \\
\hline
\end{tabular}

\begin{tabular}{lcc}
\hline Jumlah & 31 & 100 \\
\hline Tabel 2 dapat dilihat bahwa mayoritas
\end{tabular}
pendidikan ibu bersalin adalah menengah sebanyak 23 orang $(74 \%)$.

\section{Pekerjaan Ibu Bersalin}

Tabel 3 Frekuensi Pekerjaan Ibu Bersalin di RSIA Kirana, Sidoarjo

\begin{tabular}{lcc}
\hline \multicolumn{1}{c}{ Pekerjaan } & $\mathrm{f}$ & $\%$ \\
\hline Bekerja & 13 & 42 \\
Tidak Bekerja & 18 & 58 \\
Jumlah & 31 & 100 \\
\hline
\end{tabular}

Tabel 3 dapat dilihat bahwa mayoritas pekerjaan ibu bersalin adalah tidak bekerja sebanyak 18 orang (58\%).

\section{Paritas Ibu Bersalin}

Tabel 4 Frekuensi Paritas Ibu Bersalin di RSIA Kirana, Sidoarjo

\begin{tabular}{lcc}
\hline \multicolumn{1}{c}{ Paritas } & $\mathrm{f}$ & $\%$ \\
\hline Primipara & 11 & 35,4 \\
Multipara & 20 & 64,6 \\
Jumlah & 31 & 100 \\
\hline
\end{tabular}

Tabel 4 dapat dilihat bahwa mayoritas paritas ibu bersalin adalah multipara sebanyak 20 orang $(64,6 \%)$.

\section{Asuhan Sayang Ibu Persalinan Kala II}

Tabel 5 Frekuensi Asuhan Sayang Ibu pada Persalinan Kala II di RSIA Kirana, Sidoarjo

\begin{tabular}{lcc}
\hline Asuhan Sayang Ibu & $\mathrm{f}$ & $\%$ \\
\hline Dilakukan & 28 & 90,3 \\
Tidak Dilakukan & 3 & 9,7 \\
Jumlah & 31 & 100 \\
\hline
\end{tabular}

Tabel 5 dapat dilihat bahwa mayoritas ibu bersalin Kala II mendapatkan asuhan sayang ibu sebanyak 28 orang $(90,3 \%)$.

\section{Robekan Jalan Lahir}

Tabel 6 Frekuensi Kejadian Robekan Jalan Lahir di RSIA Kirana, Sidoarjo

\begin{tabular}{|c|c|c|}
\hline $\begin{array}{c}\text { Robekan Jalan } \\
\text { Lahir }\end{array}$ & $\mathrm{f}$ & $\%$ \\
\hline Terjadi & 10 & 32,3 \\
\hline Tidak Terjadi & 21 & 67,7 \\
\hline Jumlah & 31 & 100 \\
\hline
\end{tabular}

Tabel 6 dapat dilihat bahwa mayoritas ibu bersalin Kala II mendapatkan tidak mengalami robekan jalan lahir sebanyak 21 orang $(67,7 \%)$. 


\begin{tabular}{|c|c|c|c|c|c|c|}
\hline $\begin{array}{l}\text { Kejadian } \\
\text { Asuhan } \\
\text { Tabel } 7 \\
\end{array}$ & \multicolumn{6}{|c|}{$\begin{array}{l}\text { Tabulasi Silang Kejadian Robekan } \\
\text { Jalan Lahir dengan Asuhan Sayang } \\
\text { Ibu di RSIA Kirana, Sidoarjo }\end{array}$} \\
\hline \multirow{3}{*}{$\begin{array}{l}\text { Asuhan } \\
\text { Sayang } \\
\text { Ibu }\end{array}$} & \multicolumn{4}{|c|}{$\begin{array}{c}\text { Kejadian Robekan Jalan } \\
\text { Lahir } \\
\end{array}$} & \multirow{2}{*}{\multicolumn{2}{|c|}{ Jumlah }} \\
\hline & \multicolumn{2}{|c|}{ Terjadi } & \multicolumn{2}{|c|}{$\begin{array}{c}\text { Tidak } \\
\text { Terjadi }\end{array}$} & & \\
\hline & $\sum$ & $\%$ & $\sum$ & $\%$ & $\sum$ & $\%$ \\
\hline $\begin{array}{l}\text { Dilakuka } \\
\mathrm{n}\end{array}$ & 7 & 22,6 & 21 & 67,7 & 28 & $\begin{array}{c}90, \\
3\end{array}$ \\
\hline $\begin{array}{l}\text { Tidak } \\
\text { Dilakuka } \\
\text { n }\end{array}$ & 3 & 9,7 & 0 & 0 & 3 & 9,7 \\
\hline Jumlah & 10 & 32,3 & 21 & 67,7 & 31 & 100 \\
\hline
\end{tabular}

Exact Fisher's $(p)=0,027$

Tabel 7 dapat disimpulkan bahwa ibu bersalin kala II yang dilakukan asuhan sayang ibu mayoritas tidak terjadi robekan jalan lahir 21 orang $(79,57 \%)$ dibandingkan dengan ibu yang dilakukan asuhan sayang ibu yang mengalami robekan jalan lahir 7 orang $(25 \%)$.

Pada analisis hubungan kejadian robekan jalan lahir pada ibu bersalin Kala II dengan asuhan sayang ibu dan tidak asuhan sayang ibu didapatkan bahwa nilai probabilitas $(p)=0,027$ dan nilai $\alpha=0,05$ maka $\mathrm{H}_{0}$ ditolak, sehingga dapat disimpulkan bahwa ada hubungan kejadian robekan jalan lahir pada ibu bersalin dengan asuhan sayang ibu dan tidak asuhan sayang ibu di RSIA Kirana Sepanjang, Sidoarjo

\section{PEMBAHASAN}

\section{Penerapan Asuhan Sayang Ibu pada Persalinan kala II di RSIA Kirana Sepanjang Sidoarjo}

Tabel 5 menunjukkan dari ibu bersalin yang mendapat asuhan sayang ibu pada persalinan kala II sebanyak 28 (90.3\%) ibu bersalin dan yang tidak dilakukan asuhan sayang ibu $3(9.7 \%)$ ibu bersalin.

Sebagian besar ibu bersalin berpendidikan menengah (SMA) sebanyak 23 (74\%) ibu bersalin dan sebagian besar ibu bersalin tidak bekerja sebanyak 18 (58\%).

Menurut APN, 2007, dalam penerapan tindakan Asuhan Sayang Ibu (ASI) pada tindakan persalinan, petugas kesehatan memberikan pelayanan yang ramah dan sopan kepada pasien pada saat pasien bersalin datang, kemudian petugas kesehatan menjawab segala pertanyaan yang diajukan oleh pasien bersalin, kemudian mengijinkan suami atau keluarga untuk menjadi pendamping pada saat persalinan, petugas kesehatan juga melakukan pengawasan apabila ada tanda/gejala terjadinya penyulit persalinan, memberikan informasi dan konseling kepada pasien dan keluarga untuk tindakan rujukan sebagai langkah antisipasi awal apabila ada keadaan komplikasi, petugas kesehatan juga memberikan support emosional kepada pasien dan keluarga, kemudian petugas kesehatan mengatur posisi tegak seperti berjalan, berdiri, atau jongkok, memberian cairan dan nutrisi, menjaga kandung kemih agar tetap kosong dengan melakukan palpasi, pencegahan infeksi.

Pada penelitian ini didapatkan ibu bersalin yang tidak mendapat asuhan sayang ibu sebanyak 3 ibu bersalin 9.7\%. Dari hasil observasi di lapangan dapat dilihat bahwa ada sebagian bidan yang kurang memberi dukungan emosional kepada ibu seperti memberikan pujian kepada ibu dan memberikan suasana yang ramah dan aman. Hal ini juga karena faktor terlalu banyak orang di ruangan VK (ruang bersalin). Dari keluarga ibu bersalin sampai bidan dan ditambah anak-anak praktik yang membuat suasana ruangan VK (ruang bersalin) menjadi ramai.

Oleh karena itu mengingat asuhan sayang ibu sangat penting dan harus sesuai SOP (Standart Operasional Prosedur) maka bidan harus lebih memberikan asuhan sayang ibu dengan hati dan sesuai landasan asuhan sayang ibu.

\section{Kejadian Robekan Jalan Lahir di RSIA Kirana Sepanjang Sidoarjo}

Tabel 6 menunjukkan bahwa yang terjadi robekan jalan lahir sebanyak 10 (32,3 $\%)$ ibu bersalin dan tidak terjadi robekan jalan lahir sebanyak 21 (67.7\%) ibu bersalin.

Pada penelitian ini didapatkan cukup banyak ibu bersalin yang mengalami robekan jalan lahir karena yang mengalami robekan jalan lahir sebagian besar adalah ibu primipara. Ini disebabkan karena persalinan dengan tindakan yaitu episiotomi. Robekan pada jalan lahir yang disebut pula dengan rupture perineum dimana dialami pada ibu bersalin sesuai dengan dengan definisi teori yang diungkapkan oleh Wiknjosastro, 2008, 
yakni kejadian robekan (rupture perineum) dapat terjadi ketika bayi lahir baik secara normal (spontan belakang kepala), tindakan (SC) ataupun dengan alat. Kejadian robekan perineum ini pada umumnya dialami oleh ibu bersalin yang masih primipara. Apabila kepala bayi saat dilahirkan keluar terlalu cepat hal tersebut dapat menyebabkan terjadinya robekan perineum yang biasanya terjadi bagian tengah perineum secara vertikal tak berarah dan bahkan dapat meluas.

Adapun juga robekan jalan lahir dapat terjadi karena faktor ibu yang tidak mematuhi arahan dari bidan. Seperti bidan belum mengijinkan untuk meneran tapi ibu sudah meneran.

Oleh karena itu pemberian pengobatan yang tepat bila ibu bersalin mengalami robekan jalan lahir yaitu dengan memberikan uterotonika setelah lahirnya plasenta, obat ini tidak boleh diberikan sebelum bayi lahir. Uterotonika merupakan jenis obat yang bermanfaat dalam mengatasi kejadian perdarahan pada ibu bersalin dengan Kala III (Pengeluaran Plasenta) serta dapat mempercepat proses lahirnya plasenta. Rasa ketidaknyamanan ibu paca bersalin / masa nifas dapat diatasi dan dikurangi dengan melakukan perawatan pada luka perineum. Selain itu, perawatan luka perineum tersebut juga bermanfaat untuk mencegah terjadinya infeksi dan menjaga personal hygiene terutama pada bagian vulva, serta mempercepat penyembuhan luka. Hal-hal yang perlu diperhatikan antara lain mencegah kontaminasi dengan rectum, menangani dengan lembut jaringan luka, membersihkan darah yang menjadi sumber infeksi dan bau.

\section{Hubungan Penerapan Asuhan Sayang Ibu pada Persalinan Kala II dengan Kejadian Robekan Jalan Lahir di RSIA Kirana Sepanjang- Sidoarjo}

Berdasarkan Tabel 7 menunjukkan frekuensi kejadian robekan jalan lahir pada ibu bersalin yang dilakukan asuhan sayang ibu pada persalinan Kala II yang mengalami robekan jalan lahir sebanyak 7 (25\%) ibu bersalin sedangkan yang tidak terjadi robekan jalan lahir sebanyak $21(75 \%)$ ibu bersalin dan ibu bersalin yang tidak dilakukan asuhan sayang ibu pada persalinan kala II yang mengalami kejadian robekan jalan lahir sebanyak $3(9,7 \%)$ ibu bersalin.
Mochtar, 2005, pada salah satu teorinya menyatakan bahwa tanda-tanda adanya robekan perineum pada saat proses persalinan dapat diketahui apabila ditemukannya perdarahan, kontraksi uterus yang tidak adekuat, pengeluaran darah segar yang mengalir bersamaan dengan lahirnya bayi, ibu bersalin mengalami keadaan demam /menggigil, lemah dan pucat, serta adanya ketidaknormalan pada plasenta.

Prinsip tindakan episiotomi adalah pencegahan kerusakan yang lebih hebat pada jaringan lunak akibat daya regang yang melebihi kapasitas adaptasi atau elastisitas jaringan. Oleh sebab itu pertimbangan untuk melakukan episiotomi harus mengacu pada pertimbangan klinik yang tepat dan teknik yang paling sesuai dengan kondisi yang sedang dihadapi. Luka episiotomi merupakan daerah yang sulit dijaga agar tetap bersih dan kering.

Hasil penelitian menunjukkan bahwa hampir seluruhnya ibu bersalin sudah mendapat asuhan sayang ibu namun masih terjadi robekan jalan lahir. Ini dikarenakan ibu yang primipara yang harus dilakukan persalinan tindakan yaitu episiotomi untuk membantu memudahkan jalan lahir agar bayi bisa keluar. Kejadian robekan jalan lahir terjadi karena beberapa hal. Asuhan sayang ibu yang dilakukan bidan untuk ibu bersalin yang mengalami robekan adalah melakukan penjahitan pada perenium.

Hasil uji Exact Fisher's nilai $p$ adalah 0,027 yang berarti ada hubungan penerapan asuhan sayang ibu pada persalinan kala II dengan kejadian robekan jalam lahir

Oleh karena itu hal yang terpenting dalam memberikan asuhan sayang ibu pada ibu yang mengalami robekan jalan lahir adalah penanganannya yang masih harus dengan asuhan sayang ibu, karena robekan jalan lahir apabila tidak ditangani dengan baik akan terjadi komplikasi yang dapat membahayakan ibu, salah satunya adalah perdarahan. Bidan harus dapat mengetahui penyebab utama perdarahan dengan mengekplorasi jalan lahir dan bila sudah menemukan penyebab utama dari perdarahan maka selanjutnya dilakukan penjahitan.

\section{SIMPULAN DAN SARAN Simpulan}

Ada hubungan ibu bersalin dengan asuhan sayang ibu dan tidak dengan asuhan 
sayang ibu di RSIA Kirana SepanjangSidoarjo.

\section{Saran}

Diharapkan bidan dapat memberikan asuhan sayang ibu pada ibu bersalin dengan sepenuh hati dan meningkatkan pelayanan terutama asuhan sayang ibu pada ibu bersalin dan penanganan pada ibu dengan robekan jalan lahir, serta pasien diharapkan lebih mentaati anjuran dan arahan dari bidan saat proses persalinan.

\section{DAFTAR PUSTAKA}

Depkes RI.2007. Pelatihan Asuhan Persalinan Normal.Jakarta EGC. 2008. Depkes RI. Profil Kesehatan Indonesia. Jakarta : Depkes RI. 2009. Buku Kesehatan Ibu

dan Anak. Jakarta : Departemen Kesehatan dan JICA. 2010. Peraturan Menteri

Kesehatan Republik Indonesia Nomor 1464/MENKES/PER/X/2010.

Dinkes Jatim 2014. Profil Kesehatan Jawa Timur Tahun 2014. Surabaya.

Hanifa. 2008. Ilmu Kebidanan. Jakarta : PT Bina Pustaka.

Kemenkes RI., 2010. Profil Kesehatan Indonesia Tahun 2009. Jakarta.

Maimunah, Siti, 2005, Kamus Istilah Kebidanan. Jakarta: ECG.

Manuaba, I, Gede, Bagus, 2010. Ilmu Kebidanan Penyakit Kandungan dan Keluarga Berencana Untuk Pendidikan Bidan. Jakarta: ECG.
JNPK-KR. 2007. Asuhan Persalinan Normal. Jakarta: JNPK-KR/POGI, dan JHPIEGO Corporation.

Moechtar, Rustam. 2010. Sinopsis Obstetri Jilid 2. Jakarta: EGC.

Prawirohardjo, Sarwono. 2007. Ilmu Kebidanan. PTYBP.

Pusdiknakes - WHO - JHPIEGO, 2007. Asuhan Kebidanan pada Ibu Intrapartum. Jakarta: MNH

Sudi, Lawarni. 2013. Hubungan Tingkat Pengetahuan dan Sikap Ibu Primigravida Tentang Cara Meneran Terhadap Kejadian Laserasi pada Persalinan Normal Di BPS L Padang Luar Kabupaten Agam Tahun 2013. Repository Jurnal Program Studi D-III Kebidanan STIKes Prima Nusantara Vol 1, No 1.

Sambeka, Jolie. 2013. Hubungan Pengetahuan Tentang Perawatan dengan Penyembuhan Luka Episiotomi Pada Ibu Post Partum Di RSUP PROF Dr.R.D Kandau Malalayang. Jurnal Keperawatan Vol 1 No 1.

Suparman, Eddy. 2013. Hubungan Berat Badan Lahir dengan Ruptur Perenium pada Primipara Di RSUP PROF. DR. R. D. Kandau Manado. PAAI E-biomedik Vol 1, No 1.

Varney, Helen. 2007. Buku Ajar Asuhan Kebidanan Edisi 4 Volume 2. Jakarta, ECG.

Winkjosastro, Hanifa. 2008. Ilmu Kebidanan. Jakarta: PT Bina Pustaka. 